\title{
32. FECAL PELLETS AT DEEP SEA DRILLING PROJECT SITE 436
}

\author{
Peter R. Thompson, Lamont-Doherty Geological Observatory, Palisades, New York \\ and
}

Jean K. Whelan, Chemistry Department, Woods Hole Oceanographic Institution, Woods Hole, Massachusetts

\begin{abstract}
Coarse fractions of samples from DSDP Site 436 contained abundant diatoms, radiolarians, volcanic debris, rare foraminifers, and numerous fecal pellets. The morphology of four types of ovoid and rodlike pellets is described according to simple shape criteria, but are not assigned taxonomic affinity. Organic geochemical analyses reveal significant differences in the aromatic compounds pyrolyzed from the organic matrix which serve as means to distinguish pellet types. Comparison of whole sediment analyses to values derived from picked concentrates of pellet types suggests that some hydrocarbon skeletons are concentrated in the pellets. We find no evidence that ocean plate sediments typical of those recovered from Site 436 have been incorporated into the landward wall of the Japan Trench as recovered from Site 434 . This conclusion is based on the absence of fecal pellets in Site 434 sediments and on the organic matter differences between Sites 434 and 436 .
\end{abstract}

\section{FECAL PELLETS IN MARINE SEDIMENTS}

Evidence of the paleoecology of benthic organisms is extremely limited, and is based almost entirely upon traces of their foraging activity, such as burrows (mottles in cores) and fecal deposits (see reviews in Heezen and Hollister, 1971; Hanor and Marshall, 1971; Chamberlain, 1975; Pryor, 1975). The study of fecal pellets in modern nearshore environments has been facilitated by the large number of easily monitored invertebrates contributing pellets to the sediments. To a lesser extent, fecal pellets have been recovered from deep sea sediments by Murray and Renard (1891), Murray and Hjort (1912), Thorp (1931), Moore (1939), Bramlette and Bradley (1942), and Griggs et al. (1969). Holothurians and polychaetes living on or within the sediments have traditionally been considered the producers of these pellets (Murray and Hjort, 1912; Sokolova, 1959; Zenkevitch, 1963).

In recent years, pelagic sources have been investigated more closely as rapid means of transferring small particles from the photic zone to the ocean bottom (Smayda, 1969; Honjo, 1975; Roth et al., 1975). Planktonic copepods, shrimp, and salps are commonly cited as major producers of fecal pellets containing diatoms, radiolarians, coccoliths, and planktonic foraminifers. Schrader (1971) has shown that there is often little damage to diatom frustules during the copepod's digestion and excretion, and that the valves are apparently better protected against dissolution than valves precipitating individually. The sedimentation of coccoliths is also accelerated via fecal pellets, although there is some evidence that the guts of some herbivores are more destructive than others (Smayda, 1969, 1971; Honjo, 1975, 1976; Honjo and Roman, 1978).
The fate of pelagic fecal pellets is not sealed after their production. If the particles have not been altered or destroyed by the digestion of the consumer, bacteria from the gut are added to the pellets that grow in the new micro-habitat (Honjo and Roman, 1978). Growth of these autotrophic and heterotrophic organisms creates a new energy source, the pellets themselves (Johannes and Satomi, 1966). Comparison of nutrient content of fecal pellets before and after feeding experiments has confirmed coprophagy in many marine invertebrates (Frankenberg and Smith, 1967). Thus, the remains of planktonic organisms may be reprocessed many times before final burial in the sediments. The number of times pellets can be re-eaten through the water column, on the seabed, and by deposit feeders in the mud is seemingly endless, limited only by the original rate of production near the sea surface.

\section{PELLETS AT SITE 436}

The pellets collected from the coarse fractions $(>44$ $\mu \mathrm{m}$ ) of foraminifer samples from DSDP Site 436 (Figure 1; see also Thompson, this volume) are composed of fine silts and clays admixed with biogenic silica debris (Plate 2), all identical to the surrounding hemipelagic sediments. The samples were soft enough from interstitial moisture that they could be disaggregated by wetsieving with tap water alone instead of the routine procedure of adding hydrogen peroxide first. We believe that this chemical treatment would have been so detrimental to the friable pellets that it is unlikely we would have recovered them. The firmness and consistent shape of the several types of pellets (Plate 1) is evidence of their origin from benthic mud-eaters rather 


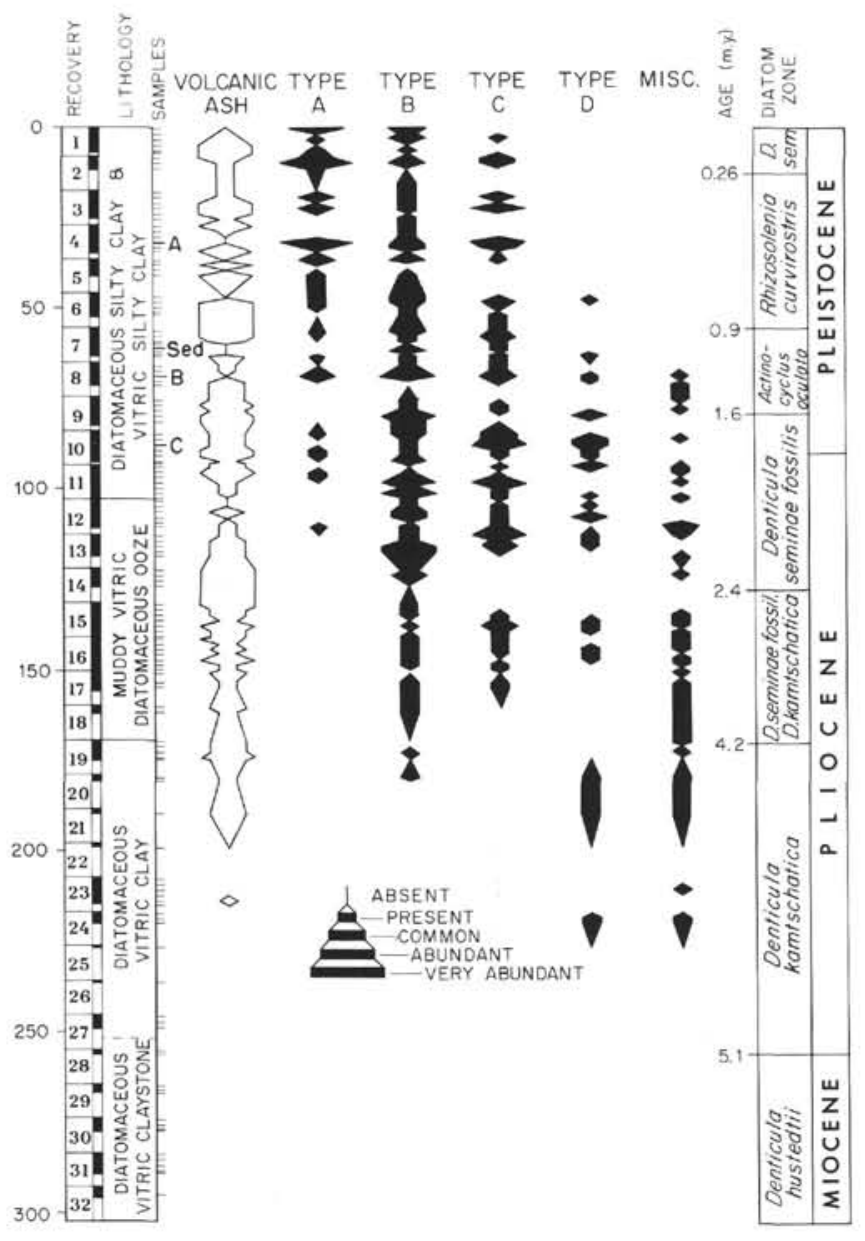

Figure 1. Abundance of fecal pellet types. Present (1-2), common (3-10), abundant (11-25), very abundant (>25); $10 \mathrm{cc}$ samples. Positions of organic geochemistry samples are indicated by " $A$, " ' $B$, " " $C$,", and "Sed."

than pelagic feeders (Schäfer, 1972). These bottom dwellers indiscriminantly process mineral matter as well as biogenic and fecal debris in their search for nutrients.

The earliest occurrence of identifiable pellets is in Sample $24, \mathrm{CC}, 5-7 \mathrm{~cm}$, from the early Pliocene Denticula kamtschatica diatom Zone (see Harper, this volume). The abundance and variety of pellet types are low and the distribution is patchy upwards through Core 17. From Core 16 to the top of the site, the increase in absolute abundance and diversity (number of morphotypes) of pellets closely mimics abundances of coarse volcanic debris. This association suggests an increase in the precipitation of biogenic silica which encouraged benthic foraging. Whether the increase in biogenic silica is related to volcanic activity or climatic change in the region cannot be determined from these samples. The only clear indications of ice-rafted materials occur in occasional samples from the late Pleistocene, but there is no apparent response in the record based on fecal pellets. We can conclude from the stratigraphic distribution of the pellets, however, that the progressive increase in abundance and diversity is related to the movement of the North Pacific plate out of the sterile regions of the central Pacific (red clays in Cores 38,39 ) towards the fertile waters off the coast of Japan. Further, pellets were not recovered from Site 434 , at the toe of the landward wall, a site drilled to sample the "accretionary wedge" for scraped-off ocean plate sediments; we find no biostratigraphic evidence of ocean plate sediments in the recovered portions of sediments at Site 434.

\section{PALEONTOLOGIC NOTES}

As discussed above, the fecal pellets have not been given taxonomic status. They are described below in order of occurrence from the top of the site downward following the methods of Moore $(1931,1939)$ and Schäfer (1972).

\section{Type A (Plate 1, Figures 1a-2b; Plate 2, Figure 1)}

Ellipsoidal to slightly elongate, about twice as long as broad; tapering gradually to rounded terminations; cross-section circular. No surface sculpturing. Light olive gray in color, firm in texture, composed of medium silt and small fragments of biogenic siliceous tests. Maximum length $0.7 \mathrm{~mm}$. Stratigraphic range late Pliocene (Core 12-6) to Recent (Core 1-1).

\section{Type B (Plate 1, Figures 3a-4b; Plate 2, Figure 2)}

Cylindrical, about twice as long as broad, with a prominent furrow extending longitudinally along the pellet; cross-section sub-circular, although slightly flattened near the groove; terminates abruptly at right angles to the long axis of the pellet, indicating separation from a longer rod. Surface smooth, without sculpturing. Light to medium olive green in color (glauconitized?), firm in texture, composed of clay and fine silt without apparent biogenic components. Maximum length $0.5 \mathrm{~mm}$. Stratigraphic range early Pliocene (Core 20-1) to late Pleistocene (Core 1-2).

\section{Type C (Plate 1, Figures 5a-7; Plate 2, Figure 3)}

Irregularly ellipsoidal in shape, about 2.5 times as long as broad; tapering gradually at both terminations; ellipsoidal in cross-section. No surface sculpturing. Gray in color, firm to slightly friable in texture, composed of medium silt with biogenic silica tests and fragments of diatoms and radiolarians. Maximum length $0.6 \mathrm{~mm}$. Stratigraphic range early Pliocene (Core 17-4) to late Pleistocene (Core 1-3).

\section{Type D (Plate 1, Figures 8a-9b; Plate 2, Figures 4-5)}

Irregularly ellipsoidal to slightly cylindrical in outline, about 2.5 times as long as broad; tapering rapidly at the terminations; cross-section subrounded. Color gray, friable texture, composed of medium silt and biogenic silica tests of diatoms and radiolarians; surface pitted where accreted particles have fallen off pellet. Maximum length $0.5 \mathrm{~mm}$. Stratigraphic range early Pliocene (Core 24) to Pleistocene (Core 6-2). 


\section{Miscellaneous Types}

Dominant in this category are small, cylindrical, pellet-like objects with a circular cross-section, dark gray in color, composed of fine silt and rare diatom fragments. Also included are occasional, very large $(1.0-2.0 \mathrm{~mm})$ pellets similar to Type A, and numerous pellets irregular in shape, probably representing deformed examples of the types described above. Range early Pliocene (Core 24) to early Pleistocene (Core 8-3).

\section{ORGANIC GEOCHEMISTRY}

The organic matter in Types A, B, and C fecal pellets was analyzed by the techniques of thermal distillation pyrolysis gas chromatography (TDPGC) and by gas chromatography mass spectrometry (GCMS). The analyzed pellets were obtained from intervals 4-4, 23-25 $\mathrm{cm}$; 8-3, 95-97 cm; and 10-3, 103-105 cm, respectively, as indicated in Figure 1. TDPGC involves heating a few pellets $(0.1-0.5 \mathrm{mg})$ in a quartz tube from 50 to $800^{\circ} \mathrm{C}$ at the rate of $40^{\circ} \mathrm{C}$ per minute. The evolved volatile organic components are swept out of the sample in a helium stream and measured as a function of temperature. For these samples, very little material was obtained by thermal distillation from 50 to about $300^{\circ} \mathrm{C}$. Most of the material emerged at a temperature of 550 to $650^{\circ} \mathrm{C}$, which represents organic molelcules pyrolyzed from, or cracked off, high-molecular-weight organic matter in each type of pellet. In addition, sediment samples taken from near the pellets (436-7-4) and from the west wall of the trench (434-15-3) were treated in a similar manner. The TDPGC technique, which is capable of examining very small samples of organic material, has not been applied previously to fecal pellets.

The purpose of these experiments was to obtain preliminary indications of the following: (1) could the fecal pellets be distinguished by the technique; (2) could the organic matter of the pellets be distinguished from the surrounding sediments; and (3) could sediment organic matter at Site 434 be distinguished from that at Site 436 ?

\section{EXPERIMENTAL}

Each sample was heated by a Chemical Data Systems "Pyroprobe" platinum coil heater. Evolved hydrocarbons were measured with a Chemical Data Systems Reaction System 820 equipped with a flame ionization detector. Part of the helium stream carrying the hydrocarbons was trapped on TENAX porous polymer (Applied Scientific Co., State College, Pa.) and analyzed further on a Varian 1400 gas chromatograph (GC) connected to a Finnegan Mass Spectrometer-Computer System. The gas chromatography column used was a $3 \mathrm{M} \times 0.6 \mathrm{~mm}$ 3\% OV-17 micropack column (Alltech Associates, Arlington Heights, Illinois).

Figures 2 and 3 show total GCMS ionization curves for the organic pyrolysate eluting from the end of the gas chromatography column. The total ion current output of the mass spectrometer is acting as the detector for the gas chromatograph. The numbers on the bottom scale refer to mass spectral scans, one scan being made approximately every 2 seconds during the GC analysis. Thus, increasing scan numbers in Figures 1 and 2 also correspond to increasing retention times of compounds eluting from the GC column. Scan 0 corresponds to about $n \mathrm{C}_{7}$ while scan 450 corresponds to about $n \mathrm{C}_{14}$. Order of elution in this particular GC column is approximately in the order of increasing boiling point or of increasing molecular weight for hydrocarbons.

The vertical lines in Figure 3 show peaks which are the same in the three curves as shown by mass spectra of the particular scans intersected. The indicated peaks, which represent xylene background from TENAX in all of our samples, were useful in determining which scans represented the same compounds in the five samples. It can be seen that the scan numbers, or retention times, vary somewhat between samples. The identities of compounds causing the peaks in Figures 2 and 3 were determined by examining the mass spectra corresponding to the scan in the center of each GC peak.

The mass spectral range examined for each of the scan numbers shown in Figures 2 and 3 was $\mathrm{m} / \mathrm{e}$ (mass per unit charge of the ion produced by electron impact of the parent molecule) of 40 through 300 . This data, which includes mass spectral fragmentation patterns for $\mathrm{m} / \mathrm{e}$ of $40-300$ for each of the five samples, was stored on a computer disk and was recalled to give a "mass chromatogram" of each GC curve shown in Figures 4 through 14. In the mass chromatograms, the GC traces shown in Figures 2 and 3 are redrawn by the computer, using only the molecular weight of a particular $\mathrm{m} / \mathrm{e}$ fragment characteristic of a particular type of compound. For example, alkylbenzenes give characteristic $\mathrm{m} / \mathrm{e}$ values at mass 105 as shown in Figure 5 .

\section{RESULTS AND DISCUSSION}

One object of this study was to see if, after heating (pyrolysis) and electron impact (in the mass spectrometer), the three types of pellets and their surrounding sediment gave characteristic fragments. It has been determined both for these samples and for other diatomaceous sediments, that pyrolysate curves such as those shown in Figures 2 and 3 are highly reproducible for any sample that is reasonably homogeneous. Figure 2 shows peaks for organic compounds from $C_{7}$ (scans 0-10) to about $\mathrm{C}_{15}$ (scan 450) which evolved during pyrolysis of sediment samples 436-7-4 and 434-15-3. It can be seen that the two curves are different, as expected for sediments from two different locations. Corresponding curves for the three types of fecal pellets are shown in Figure 3 . The early parts of the three fecal pellet curves (scans $0-150$ ) are similar, while differences occur between scans 150 and 450 . The differences are most noticeable for the Type $\mathrm{C}$ fecal pellets. The conclusion is that the organic material in the three types of pellets is different and does not break down in exactly the same manner upon heating. If the differences are reproducible from one location to another, they may be useful in characterizing the pellets.

Comparison of Figures 2 and 3 also shows that the organic matter in the Site $\mathbf{4 3 6}$ sediment is different from that in the fecal pellets. Thus, it would appear that the fecal pellets do not constitute a major unaltered organic input to sediments at Site 436. It is plausible that fecal 

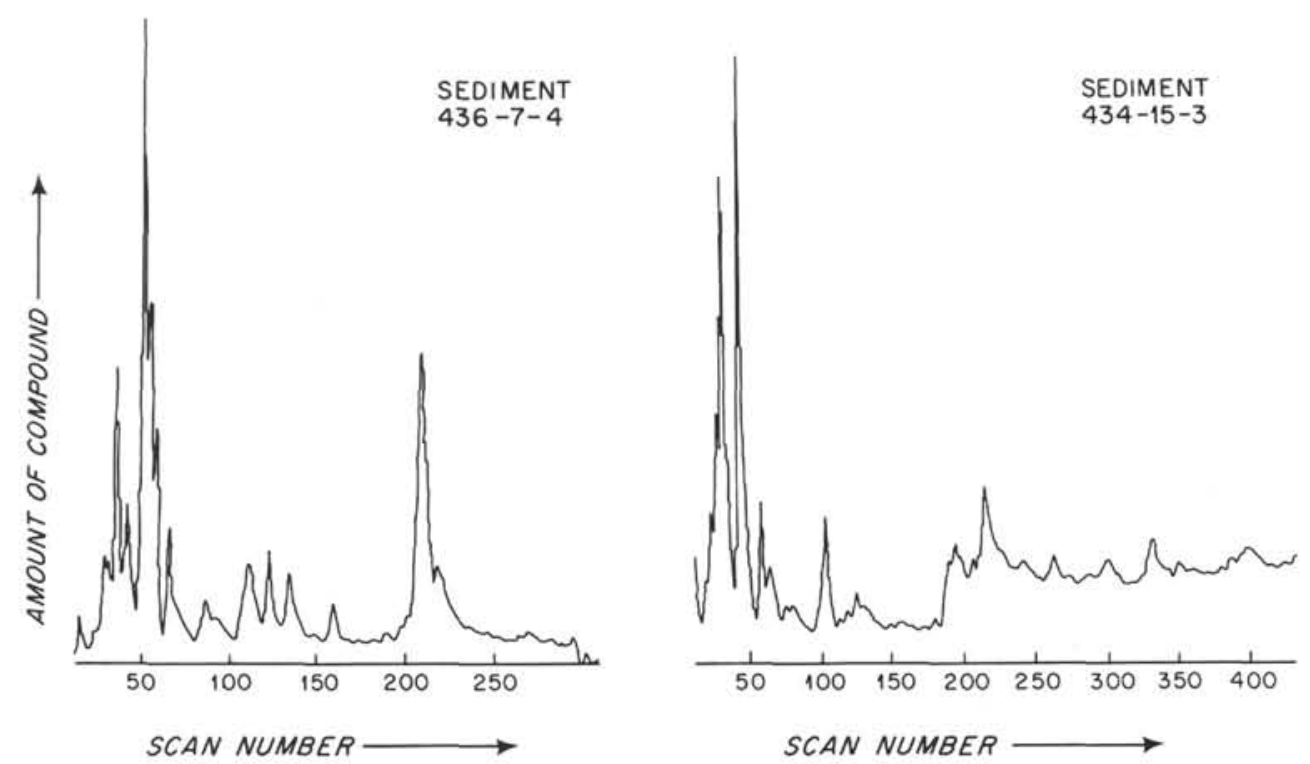

Figure 2. Mass spectral total ionization GC curves, pyrolyzed organic compounds from Japan Trench sediments. Samples 436-7-4 (east wall) and 434-15-3 (west wall).

pellets do contribute organic carbon which is subsequently attacked by microorganisms.

Various mass chromatograms of the two sediments and the three fecal pellet concentrates are shown in Figures 4 through 14 . The masses shown are characteristic primarily of some of the aromatic hydrocarbon breakdown products from these samples. It is well known that combustion and heating processes convert a part of many organic materials to aromatic hydrocarbons (see, for example, Blumer and Youngblood, 1975; Badger, 1962). Some types of compounds which have been produced in pyrolyzing these samples are shown in Figure 15 with some of their characteristic mass spectral peaks (Cornu and Massot, 1975). Many of the aromatic hydrocarbons are characterized by a strong molecular ion peak $\mathrm{M}+$ in Figure 15) which corresponds to the molecular weight of the parent compound. Also shown are some characteristic mass spectral breakdown or fragmentation peaks (indicated by $\mathrm{m} / \mathrm{e}$ ) for some of the compounds.

Mass chromatograms for masses 118 and 105 shown in Figures 4 and 5, respectively, are similar for the five samples. Similar results were obtained for masses 120 and 104 (not shown). In these initial studies, minor intensity differences are not considered to be significant, because they can be produced easily by kinetic factors related to slight organic matrix geometry differences. Presently, we do not have enough experience in applying this technique to different types of sediments and marine organic particles to say whether or not these curves would be similar for all samples derived from diatomaceous sediments, or whether the similarity is a characteristic of this particular area. The vertical lines on each figure show peaks which correspond on the three curves.

The mass chromatogram for $\mathrm{m} / \mathrm{e} 78$ (Figure 6) shows some possibly minor differences between sediment 434 and the other samples, particularly in scans 180 to 350 .
The computer automatically attenuates each mass scan so that the highest peak is set at 100 per cent of full scale. Thus, the higher baseline in sediment 434 in Figure 6 is due to electronic noise. Figure 7 shows a mass chromatogram of $\mathrm{m} / \mathrm{e}=134$ (characteristic of $\mathrm{C}_{10} \mathrm{H}_{14}, \mathrm{a} \mathrm{C}_{4}$ alkylbenzene), where real differences are discernible between the samples. Sediment 434 has a peak centered at scan 380 which is either weak or absent in the fecal pellets. Unfortunately, no data were obtained for sediment 436 in the same scan region. It also appears that this $\mathrm{m} / \mathrm{e}$ value might be useful in distinguishing Type $B$ fecal pellets from Types $A$ and $C$. The former has only weak peaks between scans 230 and 290. In addition, Type $\mathrm{C}$ has a peak at 280 as well as more complex peaks in the 200 to 220 region.

Figures 8 through 14 show mass chromatograms of $126,117,103,98,97$, and 94 , respectively. These show distinctive differences between the five samples. Mass chromatogram 126 (Figure 8) shows the two sediment samples to be very different. The scan of sediment 434 is much weaker and noisier than sediment 436 . In addition, sediment 436 shows strong peaks centered at scans 170,190 , and 200 which do not appear at all in the 434 sample. Type $\mathrm{C}$ fecal pellets show two weak peaks in the 200 region, which may correspond to those appearing in the same region in the $\mathbf{4 3 6}$ sediment sample. It can also be seen that the mass scan of Type B fecal pellets is much weaker (noisier), and that Type A pellets seem to have distinctive peaks in the 330 to 360 range. Thus, this $\mathrm{m} / \mathrm{e}$ value might be useful in distinguishing fecal pellet types.

Mass chromatogram 117 (Figure 9) also shows some distinct differences between the five samples, especially in the 170 to 200 scan region. The fecal pellets all resemble each other in this region, except for a shoulder at scan 190 in the Type A pellets. In contrast, all five samples are very similar in the 200 to 220 region. Mass spectra of these peaks indicated them to be either dihy- 


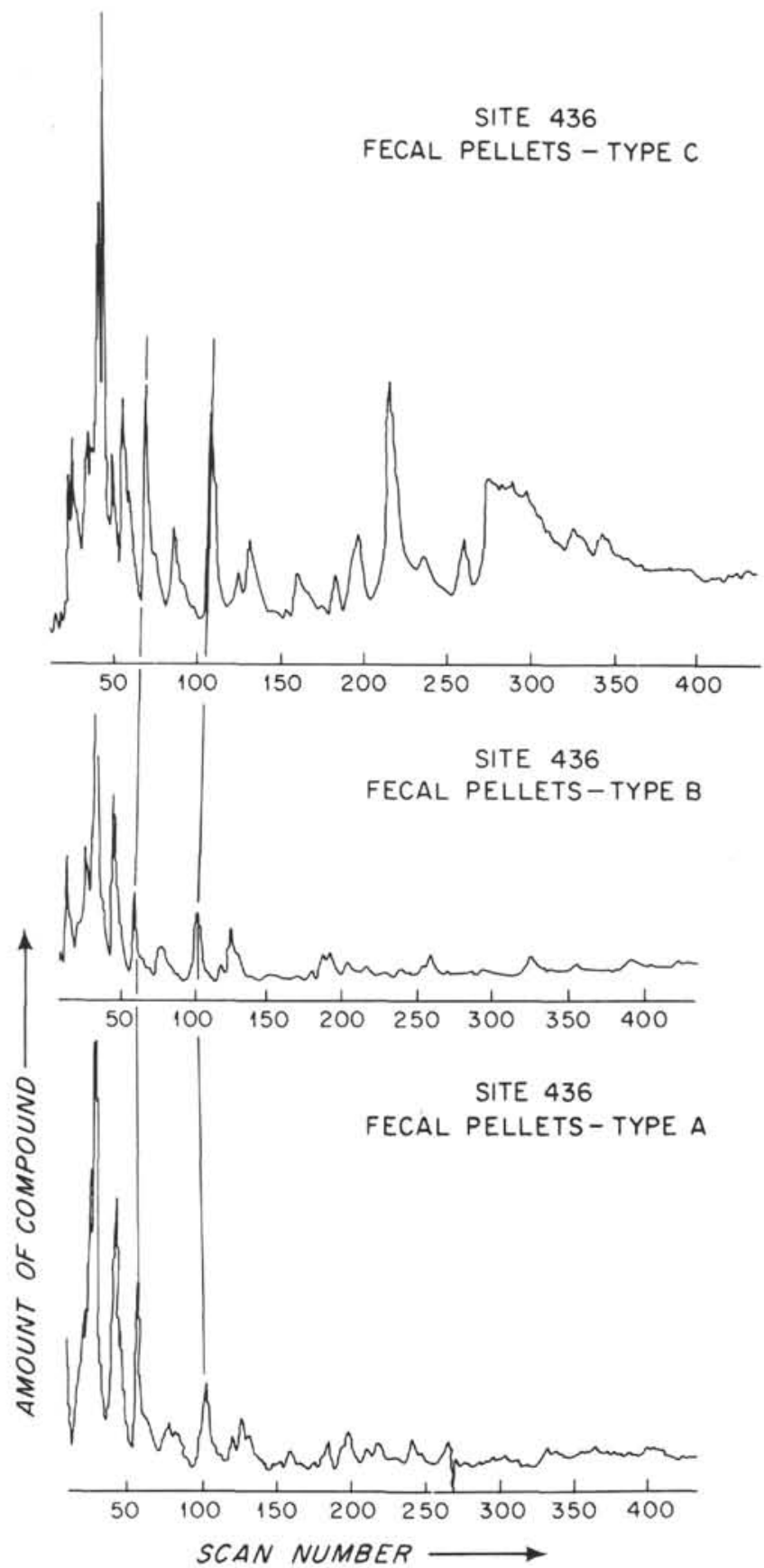

Figure 3. Mass spectral total ionization GC curves, pyrolyzed organic compounds from benthic fecal pellets, Japan Trench, Site 436 (east wall).

droindenes or methylstyrene derivatives (see Figure 15). In the 230 to 310 regions, the fecal pellet scans seem to be very similar, while the two sediment samples show differences from each other ( 434 is much weaker than 436 in this region as shown by the noise level), and from the fecal pellets.

Mass chromatograms of 103, 98, and 97 are shown in Figures 10 to 12 , respectively. The 103 scan shows only intensity differences between the two sediment samples.

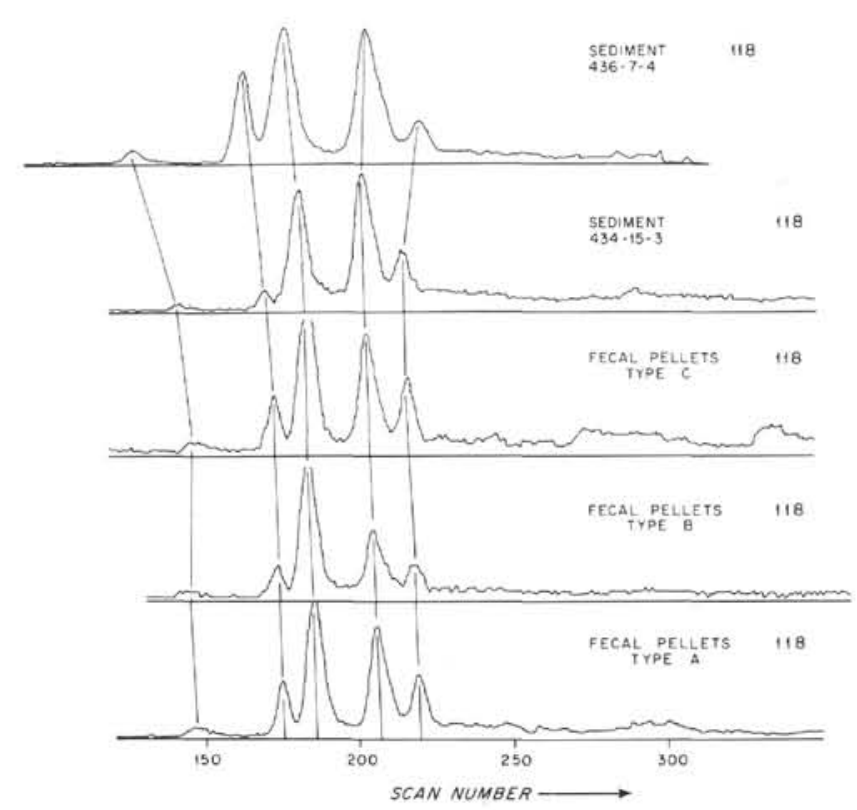

Figure 4. Mass chromatogram m/e 118. Aromatic compounds (methylsterenes).

However, these differences are strong enough so that they may be representative. Differences in the Type C fecal pellets (from the other two pellet types) are shown by the peaks centered at scans 200 and 480 . Strangely, sediment 434 resembles Type $C$ pellets in these two scan regions. Mass chromatograms of m/e 98 and 97 (Figures 11 and 12, respectively) also show distinctive differences and some similarities among the five samples. These masses are characteristic of many types of compounds, including molecular ions and fragmentation peaks of alkenes, cycloalkanes, and alkylthiophenes (see Figure 15).

Figure 13 shows mass chromatograms of m/e 94, which consists primarily of a large tailing peak centered at mass scan 220 in all samples except Type B fecal pellets (which shows a much noisier and weaker baseline). The molecule responsible for this peak is phenol (as shown by mass spectra). The presence of this particular peak may be one way of detecting the Types A and C fecal pellets.

Finally, Figure 14 shows a mass chromatogram of $\mathrm{m} / \mathrm{e} 74$. Similarities appear between scans 100 and 140 . However, scans 170 to 350 show distinctive differences. The fragment $\mathrm{m} / \mathrm{e} 74$ can be produced by breakdown of fatty acid methyl esters, as shown in Figure 15. However, it is more likely in these samples that this fragment is produced in minor amounts by deep-seated rearrangements of a number of different aliphatic and aromatic hydrocarbons.

It was noted earlier that Type B fecal pellets have a more greenish appearance than the other two types. The green color could be due to an increased iron content in the Type B pellets, possibly due to glauconitization. The presence of iron is consistent with the much weaker 


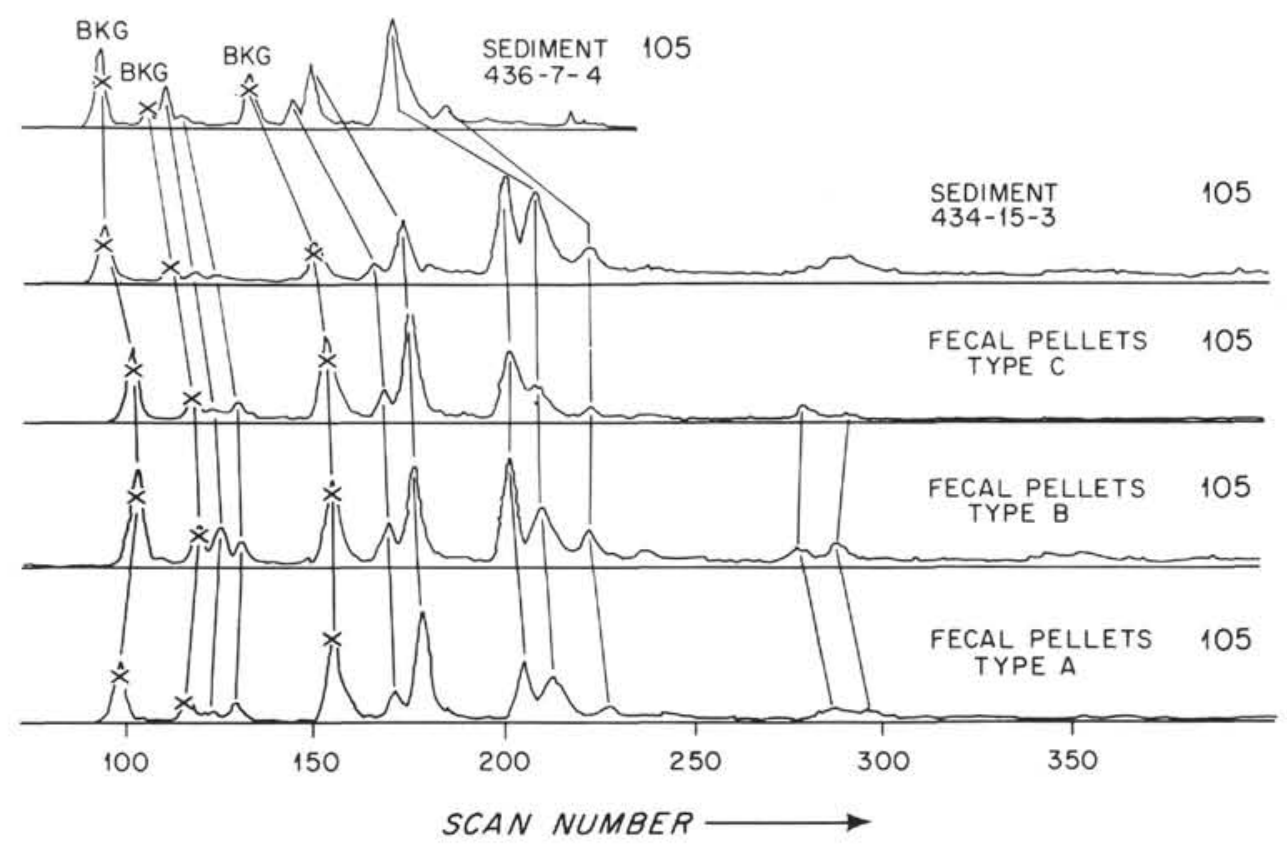

Figure 5. Mass chromatogram m/e 105. Aromatic compounds.

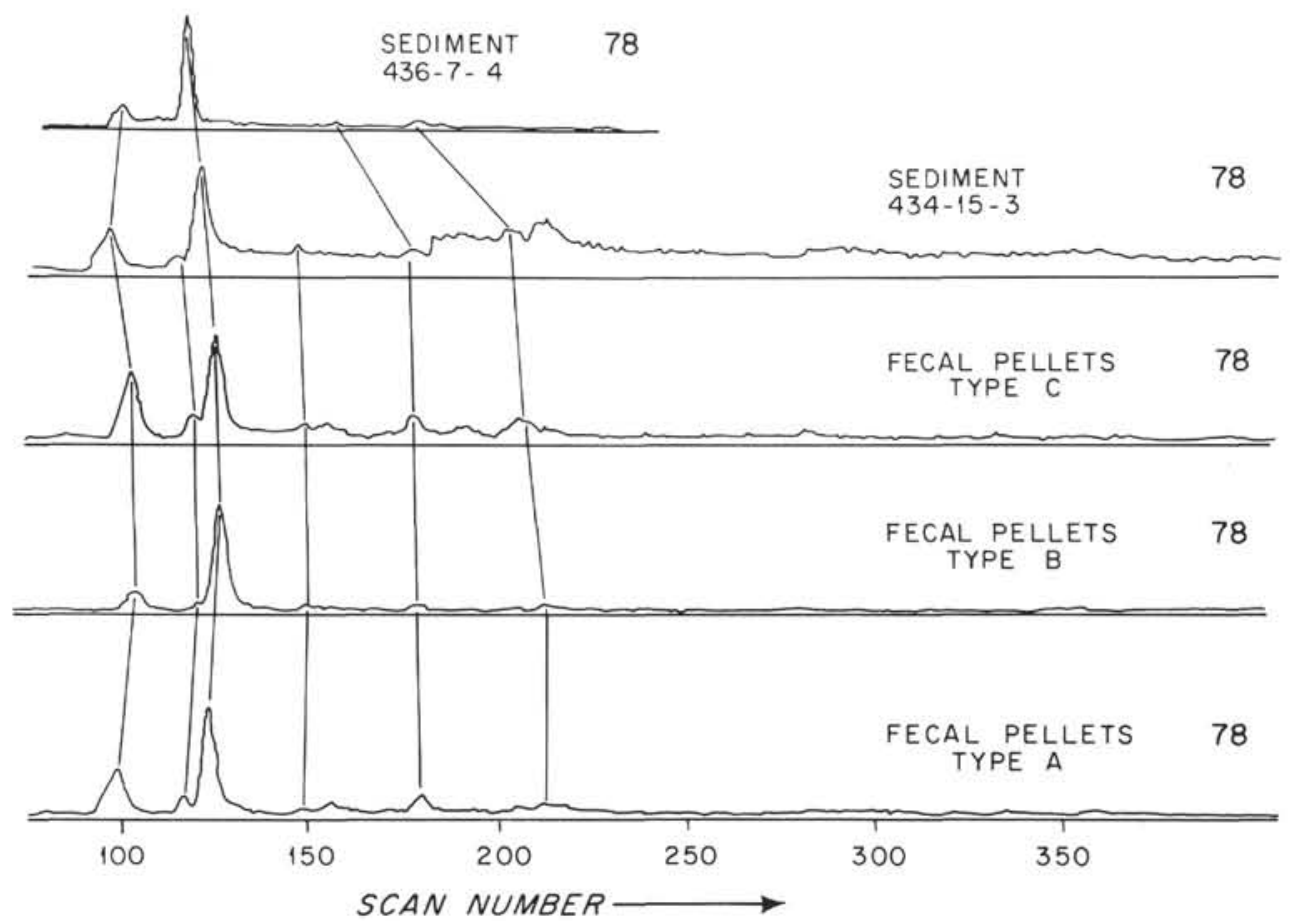

Figure 6. Mass chromatogram m/e 78. Fragments from aromatic compounds. Benzene elutes at about scan 30.

Type B mass chromatograms obtained for masses 134 , 126 , and 94 , which may represent $\mathrm{C}_{4}$ alkylbenzenes, alkylthiophenes, and phenol, respectively. These three types of compounds are particularly susceptible to freeradical decompositions (via benzylic radicals in the cases of alklylbenzenes and alkylthiophenes, or oxidation in the case of phenol), which are well known to be catalyzed by a number of different transition metals, including iron (see, for example, Walling, 1957). Thus, the weak Type B mass chromatograms may be due to ironcatalyzed decomposition of either precursors existing in the organic matrix before pyrolysis or of the molecules themselves during pyrolysis.

\section{CONCLUSIONS}

1. The stratigraphic range of the fecal pellets is from the early Pliocene to the Recent. Absolute abundances 


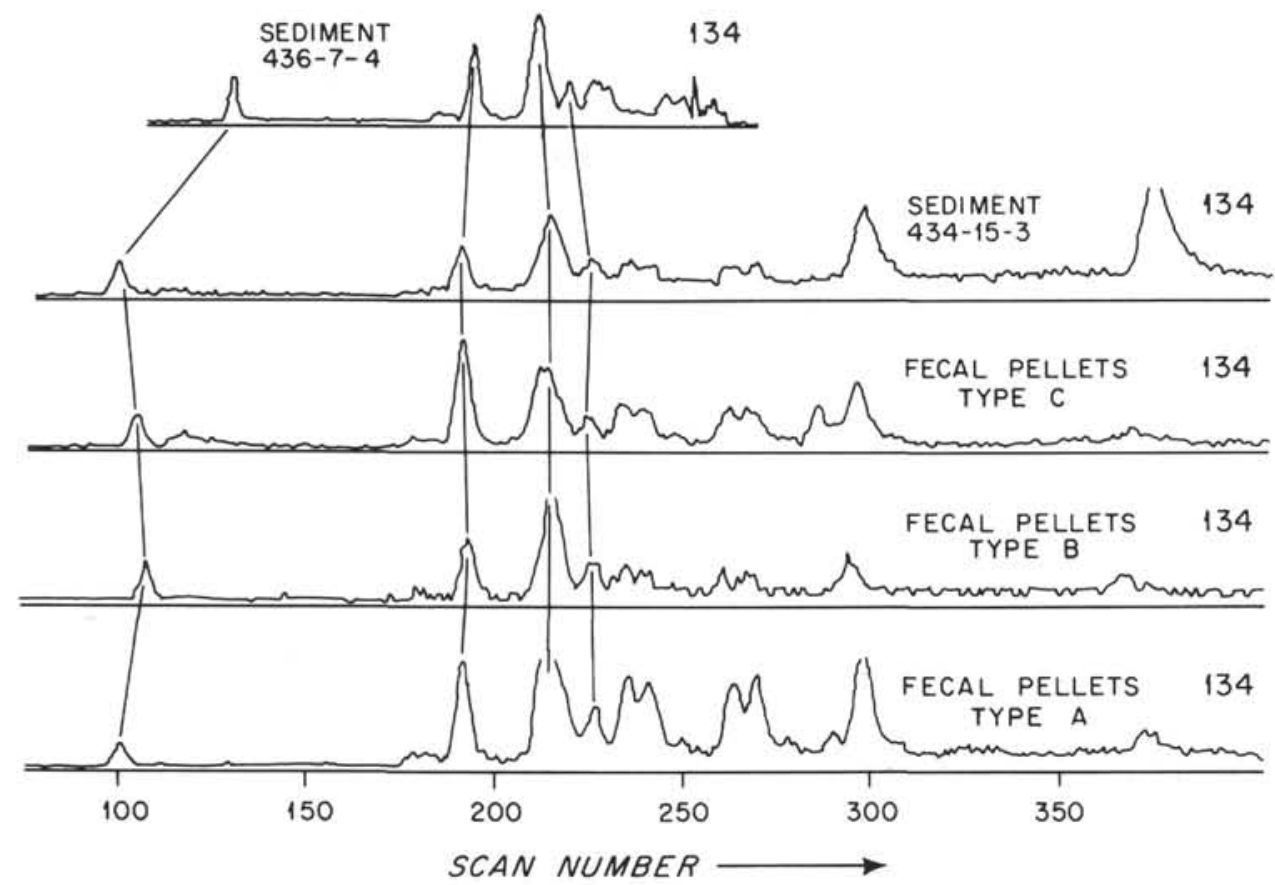

Figure 7. Mass chromatogram m/e 134. Aromatic compounds ( $C_{4}$ alkylbenzenes).

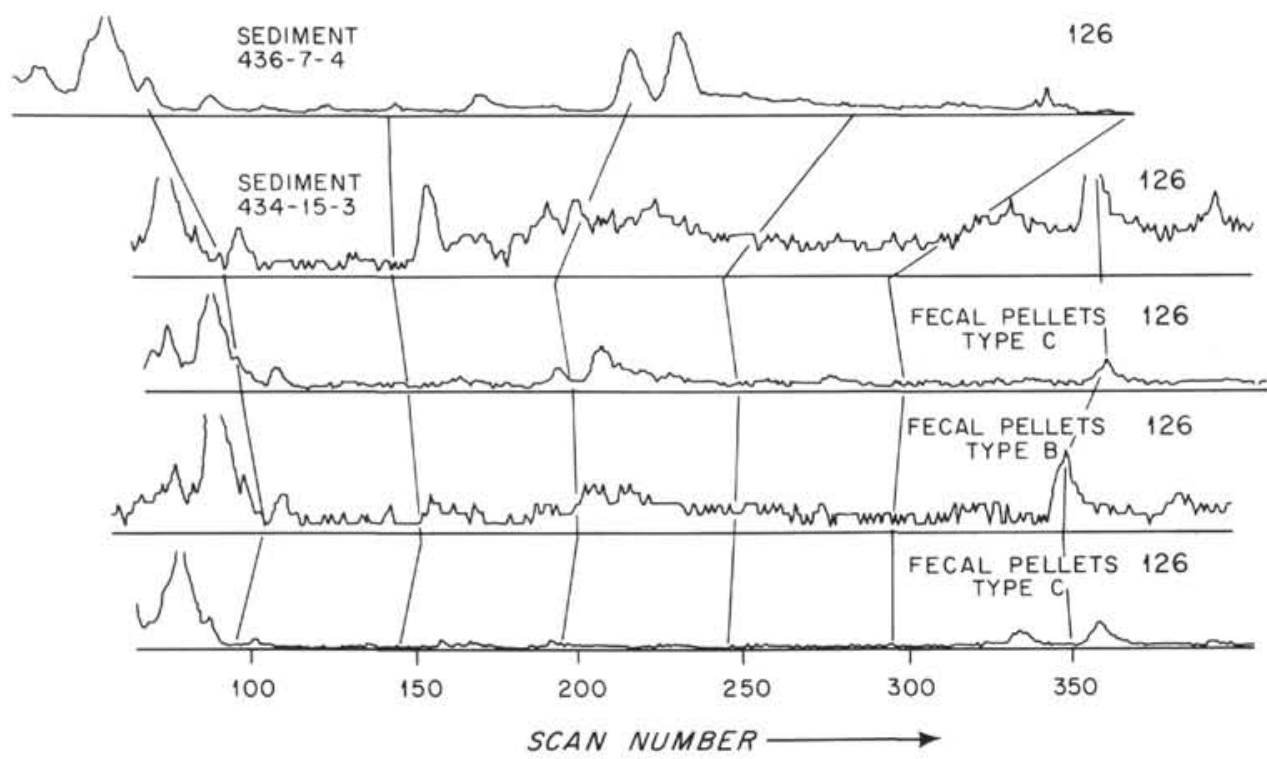

Figure 8. Mass chromatogram m/e 126.

and pellet diversity (number of morphotypes) increase upsection, and a close correspondence between coarse volcanic debris and large numbers of pellets suggests increased biogenic silica production in response to volcanic activity.

2. The gradual increase in benthic foraging may be a result of movement of the North Pacific oceanic plate out of the sterile central Pacific into the fertile waters near Japan. Absence of ocean-plate materials in the recovered sediments of Site 434 suggests that the ocean plate is being subducted with little or no formation of an accretionary wedge of ocean-plate sediments at the foot of the landward wall.

3. Organic matter from Site 434 sediments is different from that in Site 436 sediments, in spite of the primarily diatomaceous organic inputs to both sites.

4. The three types of fecal pellets examined by the techniques of thermal distillation pyrolysis gas chromatography (TDPGC) and gas chromatography mass spectrometry (GCMS) show both similarities and dif- 


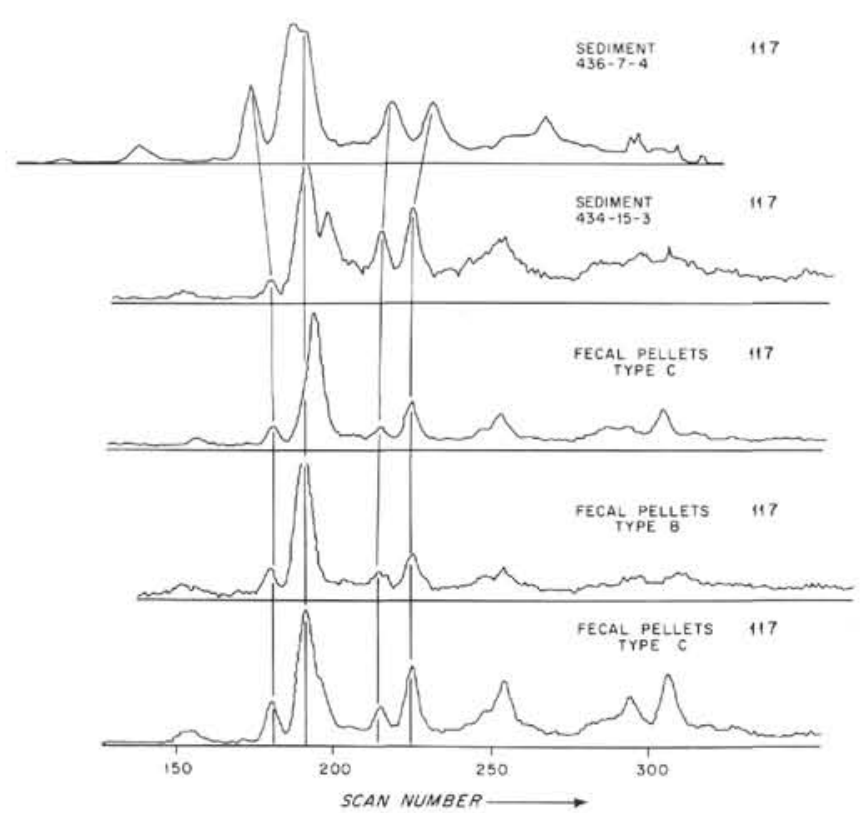

Figure 9. Mass chromatogram m/e 117.

ferences, particularly in aromatic compounds. These patterns may be usefull in characterizing each morphotype of fecal pellet.

\section{ACKNOWLEDGMENT}

Our thanks to Nelson Frew for helping with mass spectral analyses, to Dee Breger for preparation of the SEM illustrations, to Barbara Walter for drafting, and to S. Honjo and $\mathrm{M}$. Fitzgerald for reviewing the manuscript. This work was supported by National Science Foundation Grants OCE 73-26999, 75-18136, and 77-22893.

\section{REFERENCES}

Badger, G. M., 1962. Mode of formation of carcinogens in human environment. Nat. Cancer Inst. Monogr., 9, 1.

Blumer, M., and Youngblood, W. W., 1975. Polycyclic aromatic hydrocarbons in soils and Recent sediments. Science, 188, 53-55.

Bramlette, M. N., and Bradley, W. H., 1942. Geology and biology of North Atlantic deep-sea cores between Newfoundland and Ireland.. U.S. Geol. Surv., Prof. Paper 196-A, $1-50$.

Chamberlain, C. K., 1975. Trace fossils in DSDP cores of the Pacific. J. Paleont., 49 (6), 1074-1096.

Cornu, A., and Massot, R., 1975. Compilation of Mass Spectral Data (2nd ed.): New York (Heyden and Son).

Frankenberg, D., and Smith, K. L., Jr., 1967. Coprophagy in marine animals. Limnol. Oceanogr., 12 (3), 443-450.

Griggs, G. B., Carey, A. G., Jr., and Kulm, L. D., 1969. Deep-sea sedimentation and sediment-fauna interaction in Cascadia Channel and on Cascadia Abyssal Plain. DeepSea Res., 16, 157-170.

Hanor, J. S., and Marshall, N. F., 1971. Mixing of sediments by organisms. In Perkins, B. F. (Ed.) Trace fossils (SEPM Field Trip, April, 1971): Baton Rouge (La. State University), Misc. Pub. $71-1$, pp. 127-135.

Heezen, B. C., and Hollister, C. D., 1971. The Face of the Deep: New York (Oxford Univ. Press).

Honjo, S., 1975. Dissolution of suspended coccoliths in the deep-sea water column and sedimentation of coccolith ooze. In Sliter, W. V., Bé, A. W. H., and Berger, W. H. (Eds.), Dissolution of Deep-Sea Carbonates: Cushman Found. Foram. Res., Spec. Pub. 13, 114-128.

Honjo, S., and Roman, M. R., 1978. Marine copepod fecal pellets: production, preservation and sedimentation. $J$. Mar. Res., 36 (1), 45-57.

Johannes, R. E., and Satomi, M., 1966. Composition and nutritive value of fecal pellets of a marine crustacean. Limnol. Oceanogr., 11 (2), 191-197.

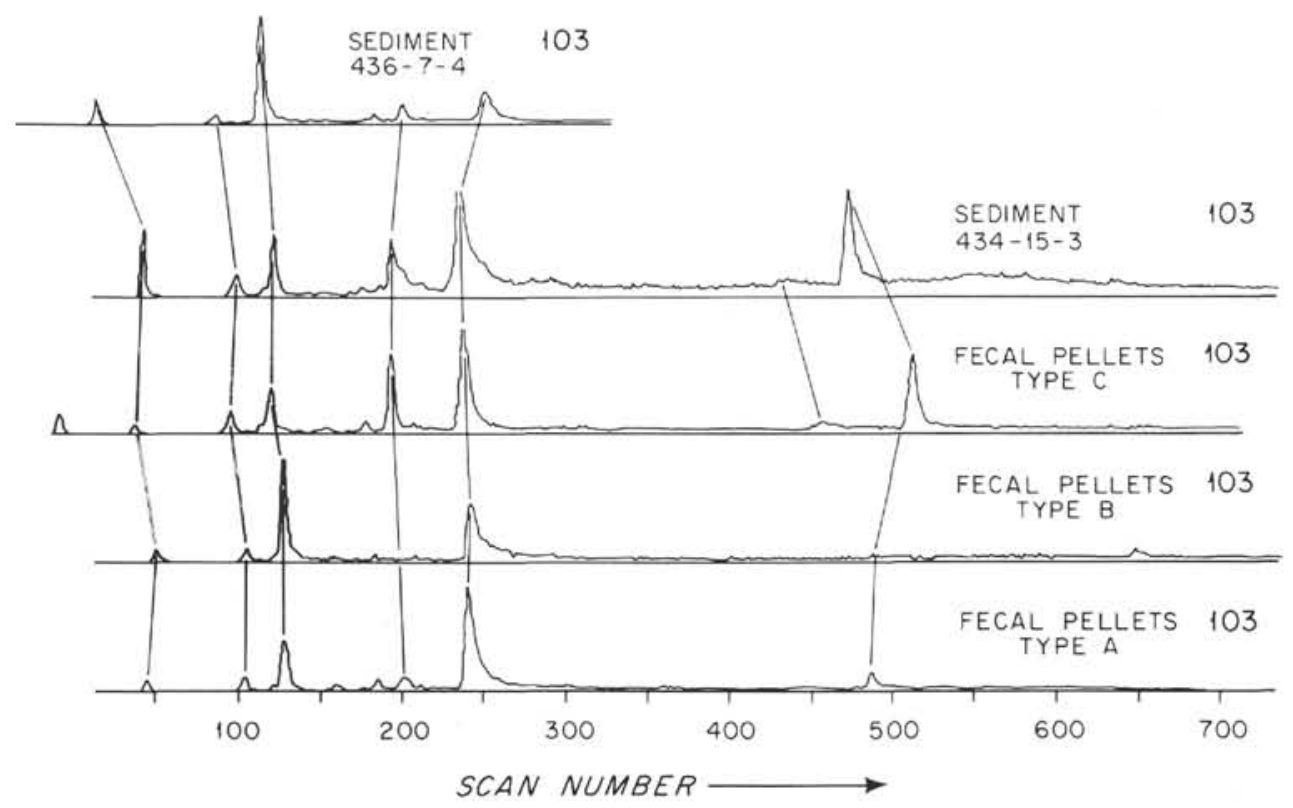

Figure 10. Mass chromatogram $\mathrm{m} / \mathrm{e}=103$. 


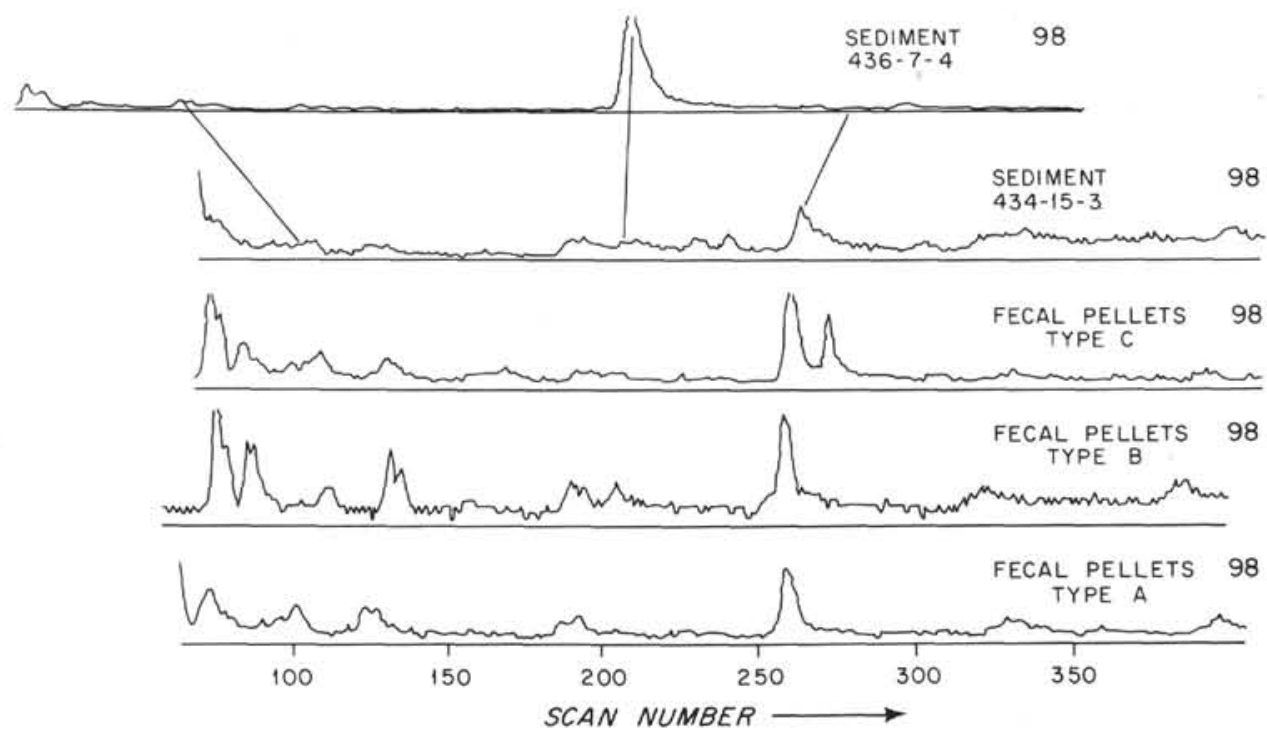

Figure 11. Mass chromatogram m/e 98. Characteristic of cycloalkanes, alkenes, decalin, and methylthiophenes.

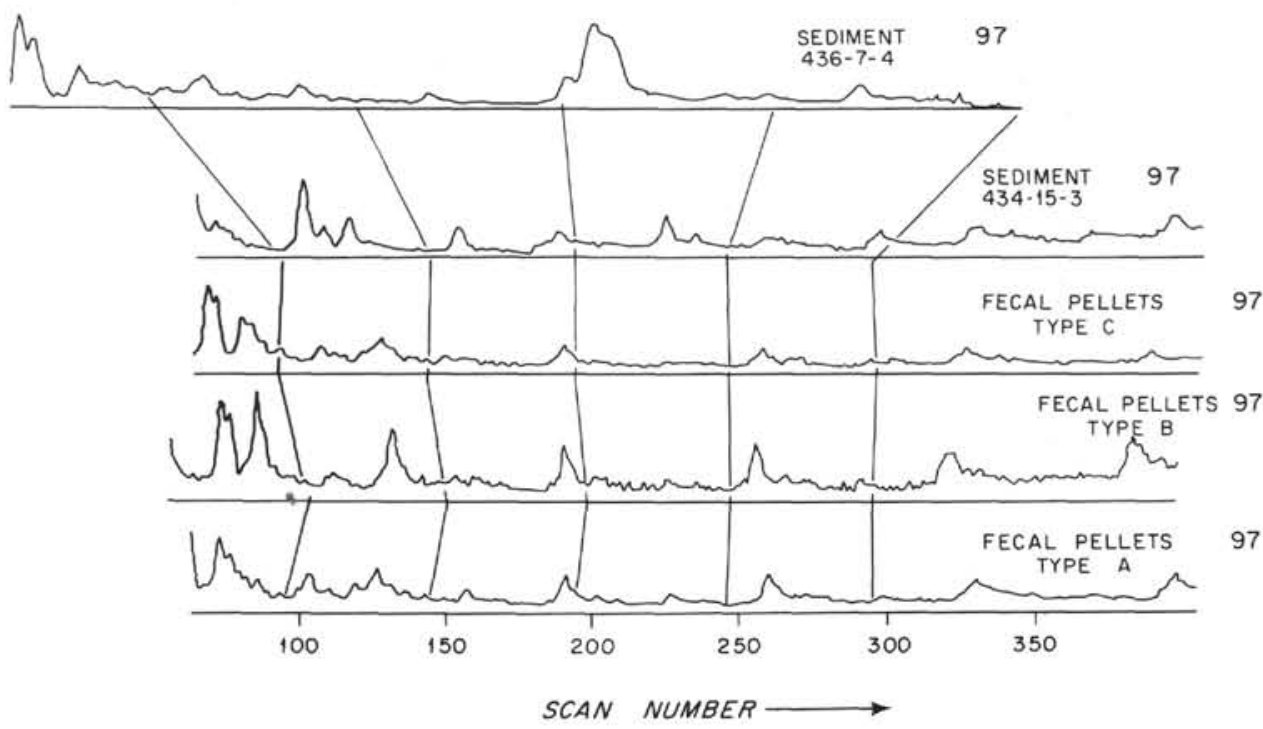

Figure 12. Mass chromatogram m/e 97. Characteristic of alkylcycloalkanes, alkylthiophenes, and alkenes.

Moore, H. B., 1931. The specific identification of faecal pellets, J. Mar. Biol. Assoc. U.K. (n. ser.) 17 (2), 359-365.

Moore, H. B., 1939. Faecal pellets in relation to marine deposits. In Trask, P. D. (Ed.), Recent Marine Sediments (reprint): New York (Dover), pp. 516-524.

Murray, J., and Hjort, J., 1912. The Depths of the Oceans (reprint): J. Cramer.

Murray, J., and Renard, A. F., 1891. Report on deep sea deposits. Rept. Sci. Res. Voyage H.M.S. Challenger.

Pryor, W. A., 1975. Biogenic sedimentation and alteration of argillaceous sediments in shallow marine environments. Geol. Soc. Am. Bull., 86, 1244-1254.

Roth, P. H., Mullin, M. N., and Berger, W. H., 1975. Coccolith sedimentation by fecal pellets: laboratory experiments and field observations. Geol. Soc. Am. Bull., 86, 10791084.
Schäfer, W., 1972. Ecology and Paleoecology of Marine Environments: Edinburgh (Oliver and Boyd).

Schrader, H. J., 1971. Fecal pellets: role in sedimentation of pelagic diatoms. Science, 174, 55-57.

Smayda, T. J., 1969. Some measurements of the sinking rate of fecal pellets. Limnol. Oceanogr., 14, 621-625.

Smayda, T. J., 1971. Normal and accelerated sinking of phytoplankton in the sea. Mar. Geol., 11, 105-122.

Sokolova, M. N., 1959. On the distribution of deep-water bottom animals in relation to their feeding habits and the character of the sediment. Deep-Sea Res., 4, 1-4.

Thorp, E. M., 1931. Descriptions of deep-sea bottom samples from the western North Atlantic and the Caribbean Sea. Bull. Scripps Inst. Oceanogr., Tech. Ser., 3, 1-31.

Walling, C., 1957. Free Radicals in Solution: New York (Wiley).

Zenkevitch, L., 1963. Biology of the Seas of the U.S.S.R.: New York (Interscience). 


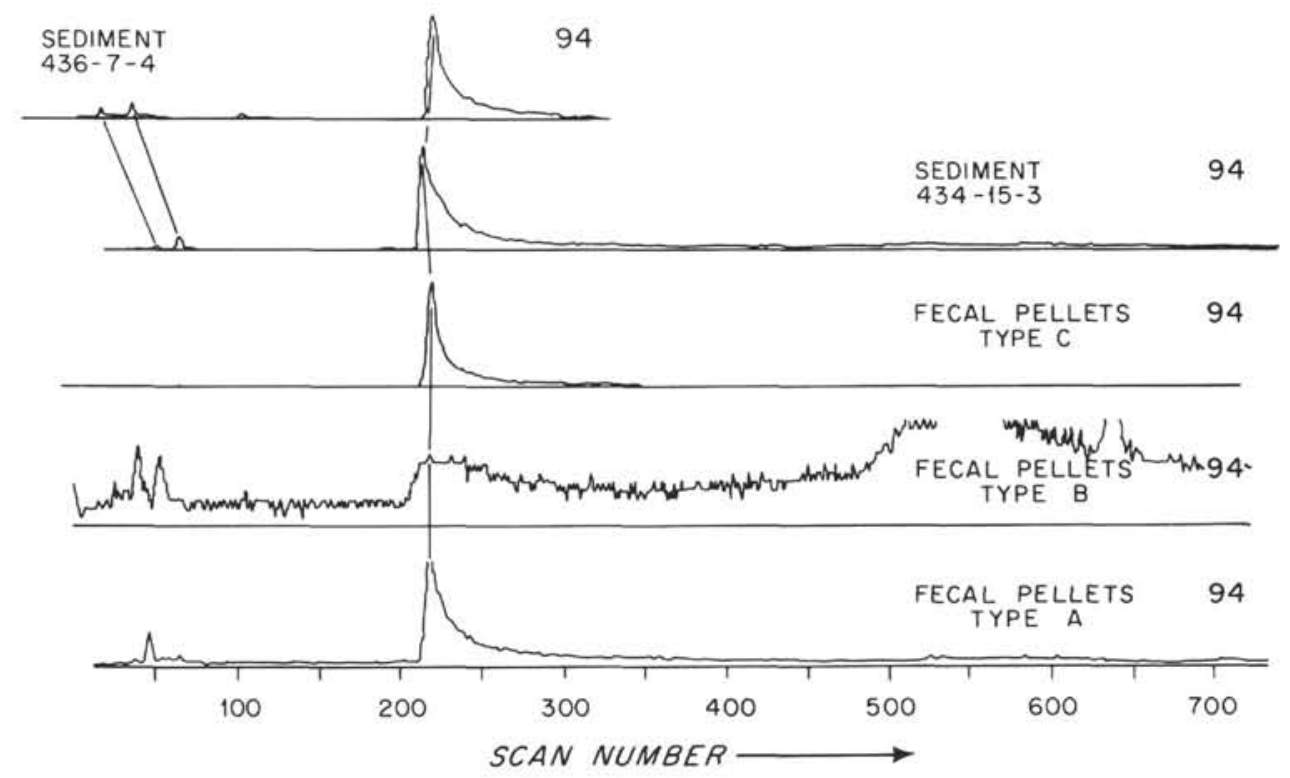

Figure 13. Mass chromatogram m/e 94. Strong peak centered at about scan 220 is phenol.

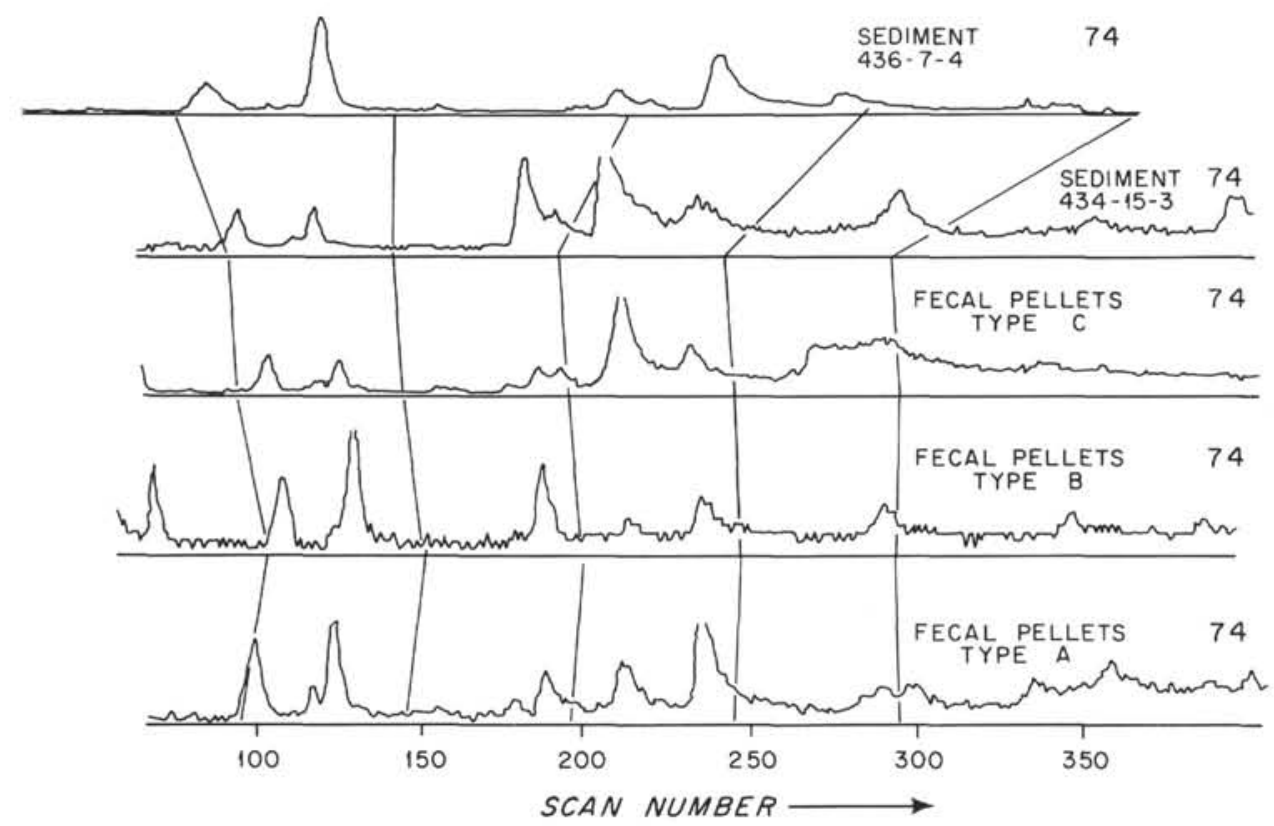

Figure 14. Mass chromatcgram m/e 74. 
<smiles>CCc1ccccc1CC</smiles>

$\oplus$

$M^{+}=120$

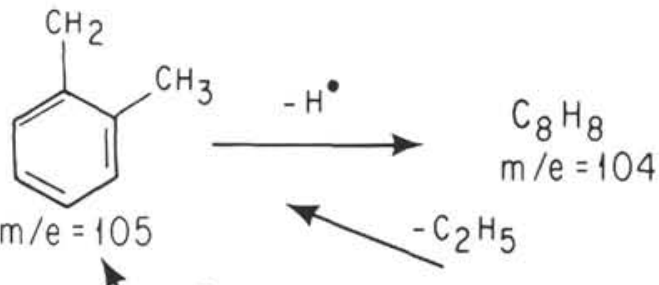<smiles>[R]CCCCCC</smiles>

$\mathrm{M}^{+}=\mathrm{C} n \mathrm{H} 2 \mathrm{n}-6$

$\mathrm{m} / \mathrm{e}=91$<smiles>c1ccc(-c2ccccc2)cc1</smiles>

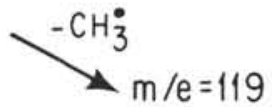<smiles>Oc1ccccc1</smiles>

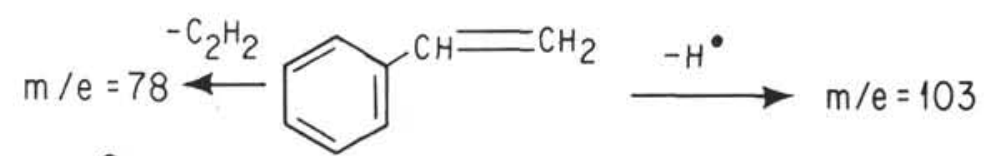

Phenol $M^{+}=94$

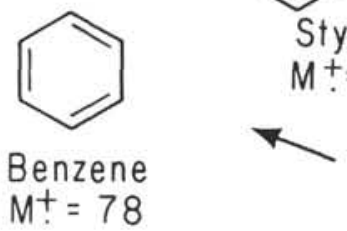

$\mathrm{CH}_{3}$

Methylstyrene

2,3-Dihydroindene<smiles>C=Cc1ccccc1</smiles>

$M^{+}=118$<smiles>c1ccc2c(c1)CCC2</smiles>

$M^{+}=118$<smiles>CC1CCCCC1</smiles><smiles>[R]CCC</smiles><smiles>CC1C[C-]CCC1</smiles>
$\mathrm{m} / \mathrm{e}=97$<smiles>[X]c1ccccc1</smiles>

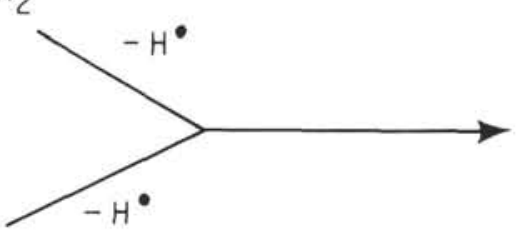
$\mathrm{m} / \mathrm{e}=117$ Propylthiophene

Methyl alkyl cyclohexane
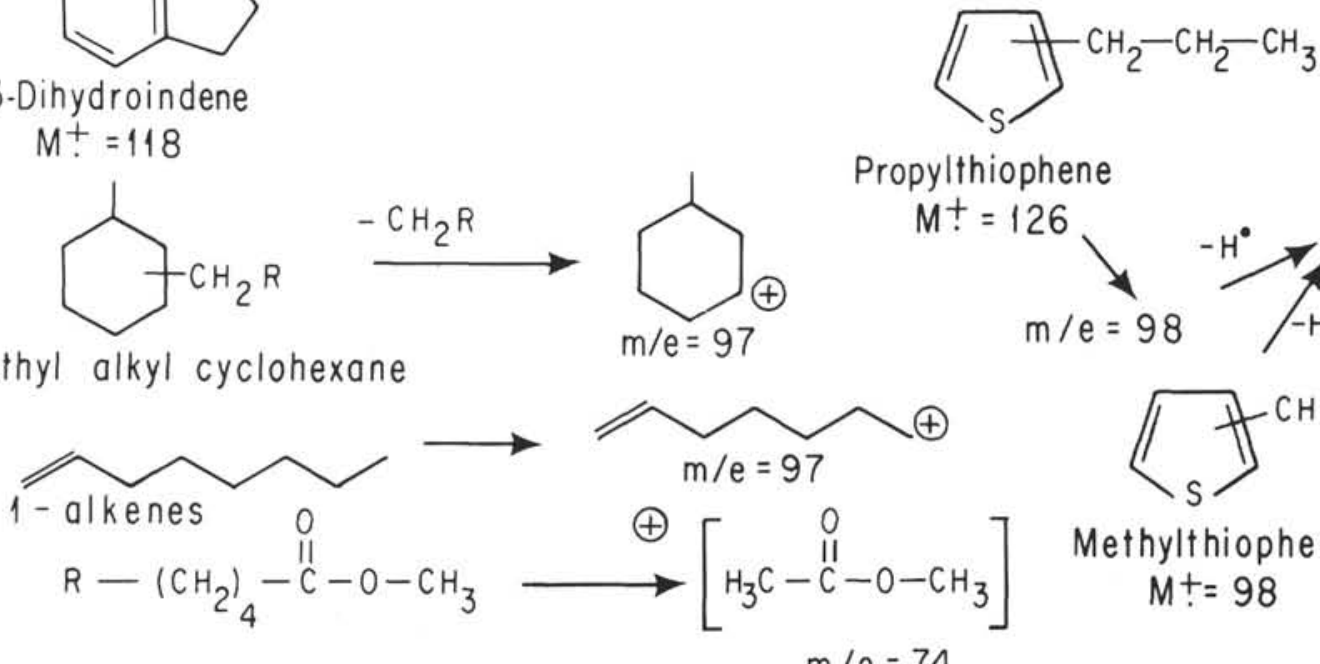

Fatty acid methyl esters $\mathrm{m} / \mathrm{e}=74$

Figure 15. Some types of compounds and their mass spectral fragments produced by pyrolyzing fecal pellets and sediments. Molecular ions (corresponding to parent compound molecular weight) indicated by $\mathrm{M}^{+}$; fragment ions indicated by $\mathrm{m} / \mathrm{e}$. 


\section{PLATE 1}

Fecal Pellets from Site 436;

(" $a$ " and " $b$ " denote different views of a single pellet.)

Figures 1a-2b Type A from Core 4, Section 4, 23-25 cm, $\times 100$. 1a, $2 \mathrm{a}$ : longitudinal views; $1 \mathrm{~b}, 2 \mathrm{~b}$ : end views.

Figures 3a-4b Type B from Core 11, Section 4, 23-25 cm, $\times 100$. 3a, 4a: longitudinal views; $3 \mathrm{~b}, 4 \mathrm{~b}$ : end views.

Figures 5a-7 Type $\mathrm{C}$ from Core 11, Section 4, 23-25 cm, $\times 100$. $5 \mathrm{a}, 6$ : longitudinal views; $5 \mathrm{~b}, 7$ : end views.

Figures 8a-10 Type D from Core 24, Section 2, 43-45 cm, $\times 65$. $8 \mathrm{a}, 9 \mathrm{a}$ : longitudinal views; $8 \mathrm{~b}, 9 \mathrm{~b}, 10$ : end views. 
PLATE 1
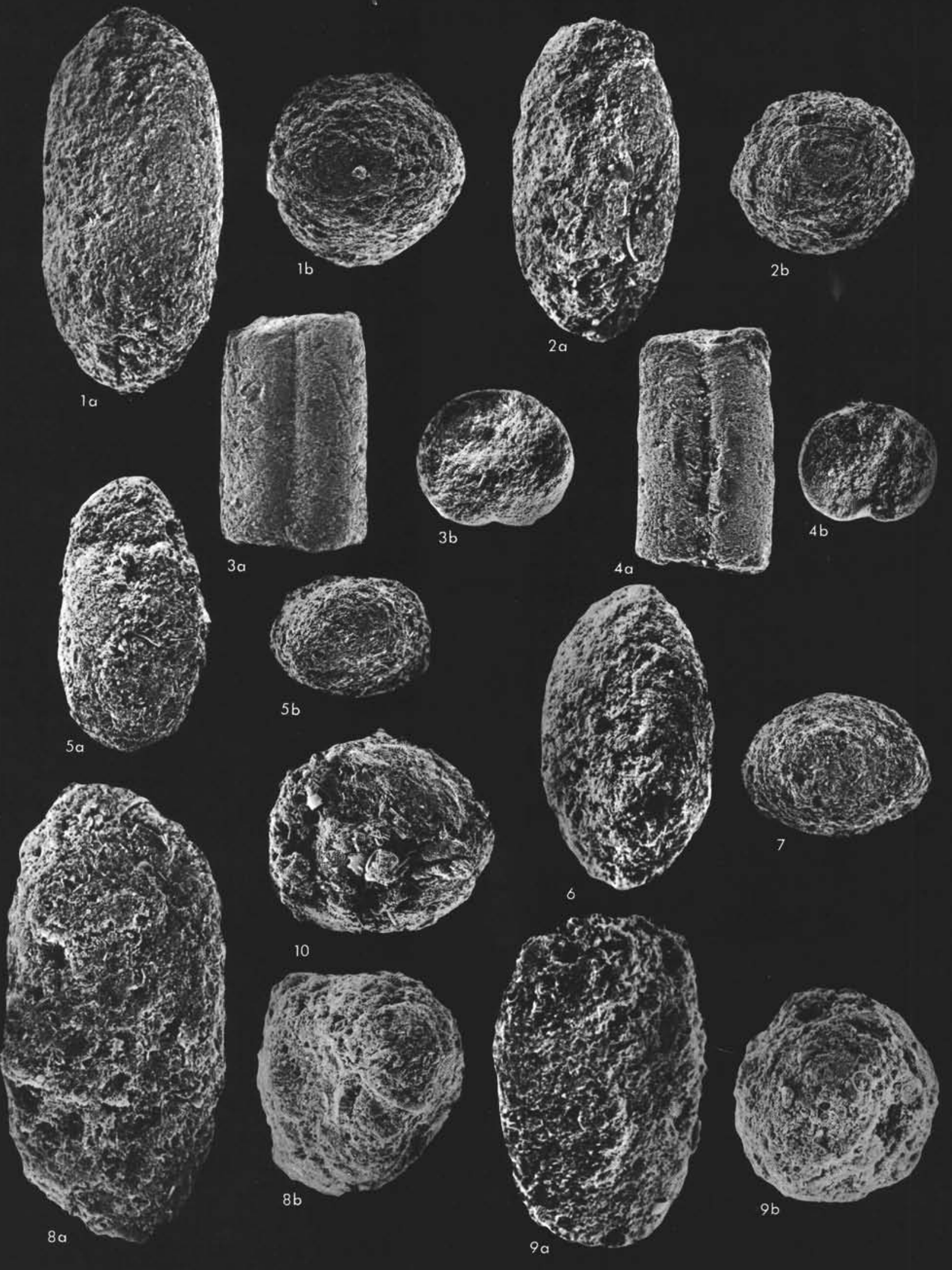


\section{PLATE 2}

Fecal Pellets from Site 436

Figure 1

Type A from Core 4, Section 4, 23-25 cm, $\times 1070$. Enlargement showing siliceous biogenic debris and clay (?) minerals.

Figure 2 Type B from Core 11, Section 4, 23-25 cm, $\times 624$. Enlargement of longitudinal groove. Biogenic siliceous debris is generally rare.

Figure 3 Type $\mathrm{C}$ from Core 11, Section 4, 23-25 cm, $\times 490$. Enlargement to show diatom fragments and minerals.

Figure 4 Type D from Core 24, Section 2, 43-45 cm, $\times 490$. Enlargement to show diatom fragments and minerals.

Figure 5 Type D from Core 24, Section 2, 43-45 cm, $\times 490$. Enlargement of radiolarian fragment. 
PLATE 2

Fin:

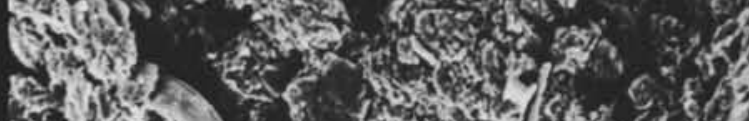

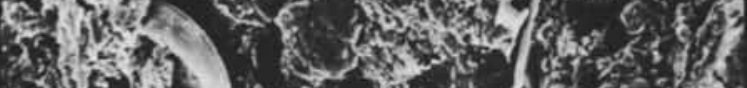

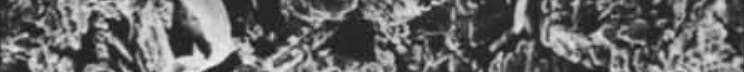

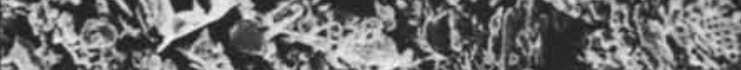

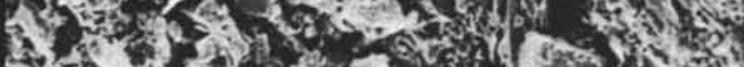

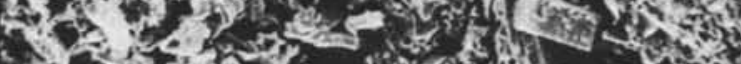

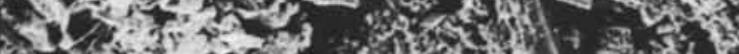

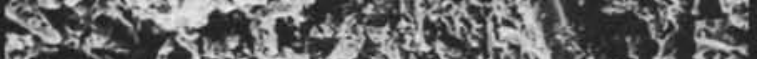
B.

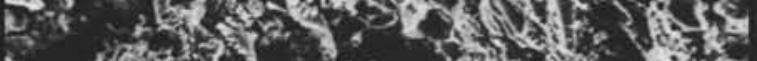

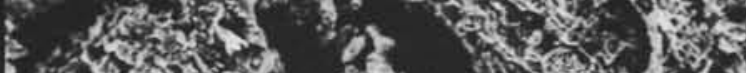

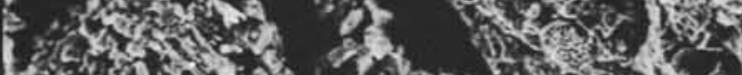
S.M.

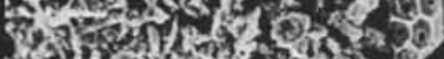

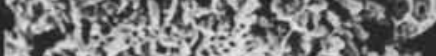

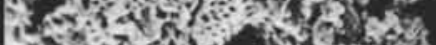

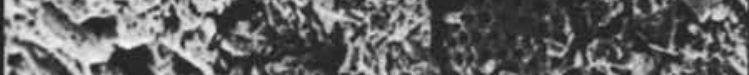

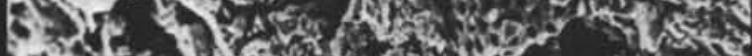

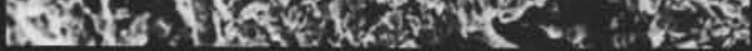

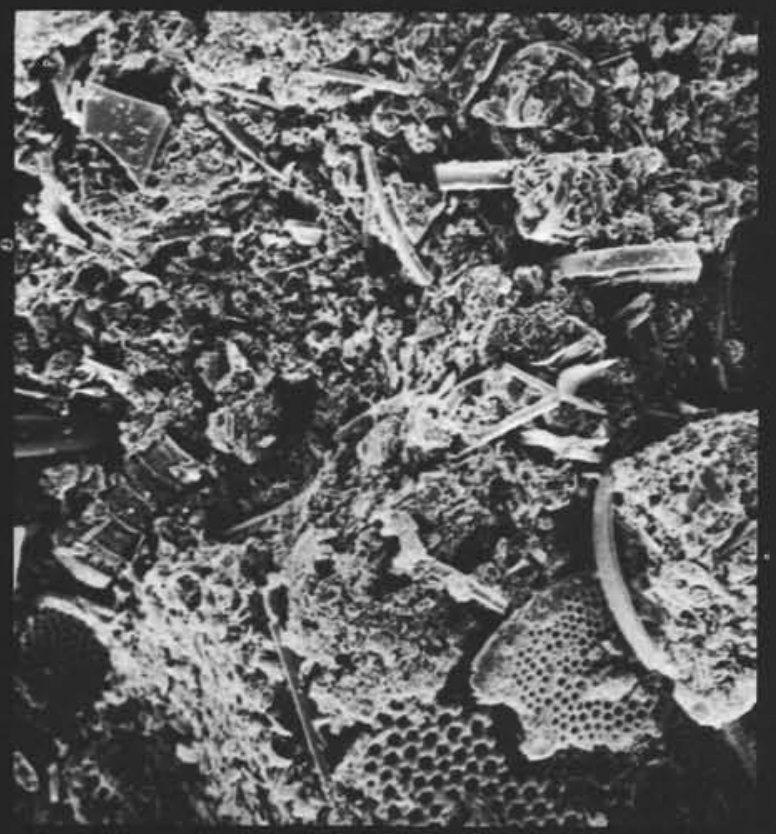

3

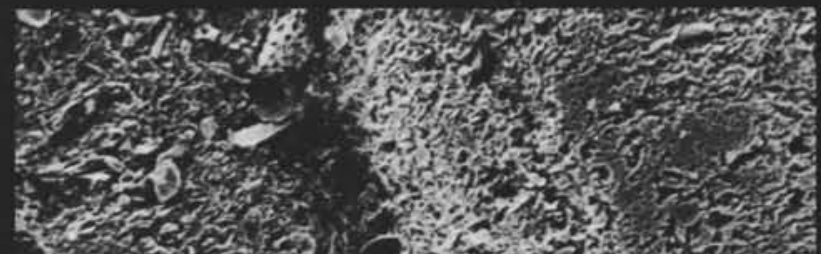

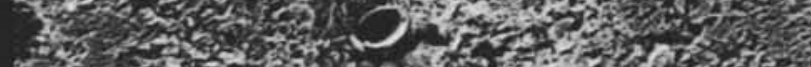

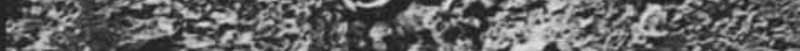

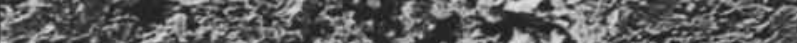

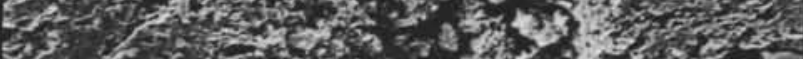

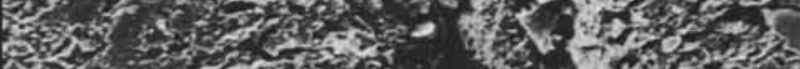

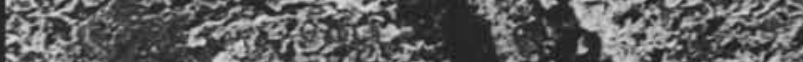

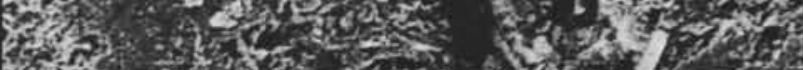

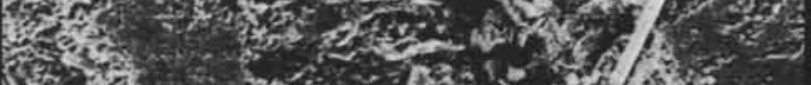

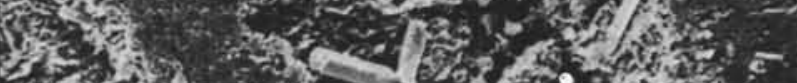

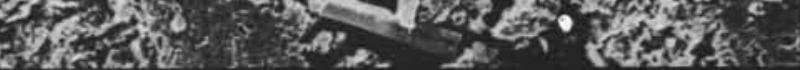
2

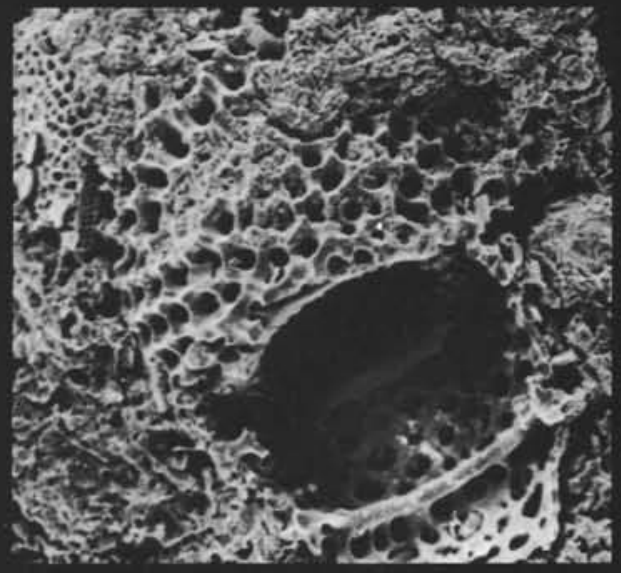

5

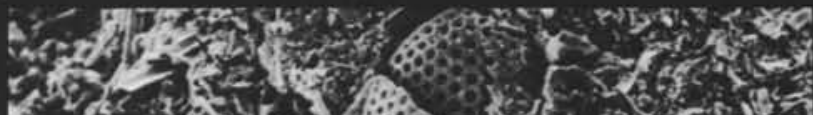
s.

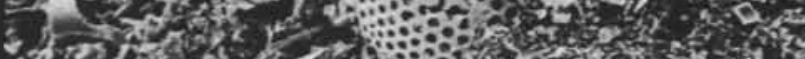

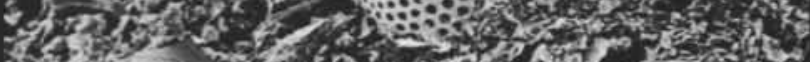
3.

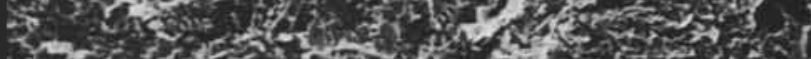

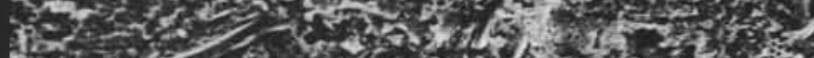

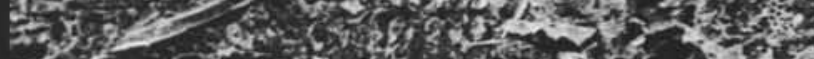

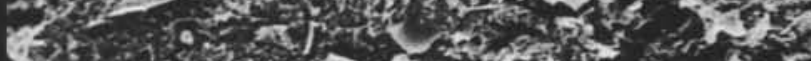

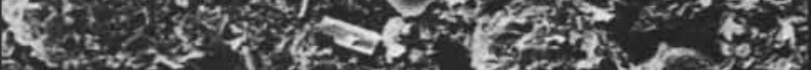

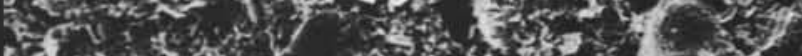

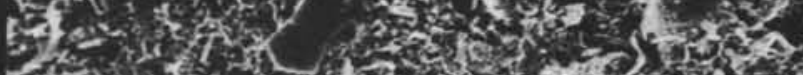

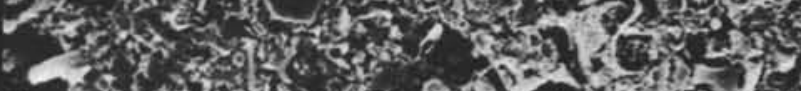

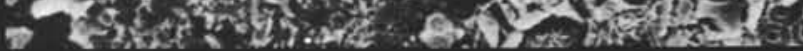

